\title{
O CONSTITUCIONALISMO AMBIENTAL COMO MECANISMO REGULADOR DO EQUILÍBRIO SOCIOAMBIENTAL PARA AS GERAÇÕES PRESENTES E FUTURAS
}

\author{
THE CONSTITUTIONALISM AS ENVIRONMENTAL REGULATORY MECHANISM OF \\ ENVIRONMENTAL BALANCE FOR THE PRESENT AND FUTURE GENERATIONS
}

LUÍS MARCELO MENDES Mestrando em Direito pela Universidade Federal de Santa Maria na Linha Direitos da Sociobiodiversidade. Especialista em Direito Constitucional Contemporâneo pela Universidade de Passo Fundo. Graduado em Direito pela Universidade Luterana do Brasil. E-mail: luis.marcelo@ulbra.br

\section{RESUMO}

O artigo realiza um diagnóstico sobre a atuação do constitucionalismo ambiental como mecanismo regulador do equilíbrio socioambiental para as gerações presentes e futuras frente o processo de globalização econômica. Sob o aspecto metodológico, a pesquisa vale-se do método dedutivo para realizar uma análise ampla, valendo-se de aportes dialéticos para findar o processo de análise. A globalização econômica influencia na construção de um novo modelo de sociedade calcada no consumo, que impede a implantação um modelo calcado no desenvolvimento sustentável desatrelado da lógica do capital. Por fim, será analisado como o constitucionalismo ambiental pode atuar como marco regulatório do equilíbrio socioambiental para as gerações presentes e futuras, regulando a degradação ambiental provocada pelas relações de consumo.

Palavras-chave: Constitucionalismo ambiental; Globalização econômica; Equilíbrio socioambiental.

\begin{abstract}
The paper makes an assessment of the environmental performance of constitutionalism as a regulatory mechanism of the environmental balance for present and future generations forward the process of economic globalization. Under the methodological aspect, the research makes use of the deductive method to conduct a comprehensive analysis, drawing on contributions to ending the dialectical process of analysis. Economic globalization influences the construction of a new model of society grounded in consumption, which prevents implantation in one uncoupled sustainable development underpinned the logic of capital model. Finally, we will analyze how the environmental constitutionalism can act as regulatory framework of environmental balance for present and future generations, regulating the environmental degradation caused by consumer relations.
\end{abstract}

Keywords: Environmental constitutionalism; economic globalization; Environmental balance.

\section{SUMÁRIO}

INTRODUÇAO; 1 A GLOBALIZAÇÃO ECONÔMICA E O PROCESSO DE DEGRADAÇÃO SOCIOAMBIENTAL; 20 CONSTITUCIONALISMO AMBIENTAL COMO MARCO REGULATÓRIO DO EQUILÍBRIO SOCIOAMBIENTAL PARA AS GERAÇÕES PRESENTES E FUTURAS; CONCLUSÃO; REFERÊNCIAS. 


\section{INTRODUÇÃO}

O processo de globalização econômica, iniciado com mais afinco a partir de 1960, deflagrou uma mudança radical no modo de vida em escala global. Essas mudanças desencadearam um impacto negativo na questão da preservação ambiental, haja vista, que existe uma supremacia da economia sobre as demais áreas sociais. Nesse sentido, é preciso repensar o papel do direito, em especial, através do processo de constitucionalização da questão ambiental no afã de criar mecanismos eficientes para garantir um modelo de desenvolvimento sustentável que resguarde o direito ao meio ambiente sadio e ecologicamente equilibrado para as gerações presentes e futuras.

Sob o aspecto metodológico, usar-se-á o método dedutivo no intuito de realizar um diagnóstico amplo da temática, a fim de pontuar aspectos relevantes acerca do fenômeno analisado. Após far-se-á uso de aportes dialéticos para concluir o processo de análise, uma vez, que é preciso confrontar as práxis da efetivação do constitucionalismo ambiental na proteção do acesso ao meio ambiente sadio e ecologicamente equilibrado para as gerações presentes e futuras.

Num primeiro momento, buscar-se-á delinear aspectos importantes das tensões ocasionadas pela globalização da economia na sociedade contemporânea oriundas das relações de consumo. Destacando como o processo de globalização econômica tem afetado as questões de cunho ambiental, através da mudança nas interações sociais dos sujeitos, que passam da condição de cidadãos para a de consumidores com objetivo de atender a lógica imposta pelo mercado.

Posteriormente, procurar-se-á demonstrar que o constitucionalismo ambiental pode atuar como marco regulatório na construção de um meio ambiente sadio e ecologicamente equilibrado para as gerações presentes e futuras, regulando em especial, a degradação ambiental provocada pelas relações de consumo. Para tanto, analisar-se-á a gênese da contaminação dos sistemas constitucionais contemporâneos, deflagrada pela Conferência de Estocolmo a partir de um breve estudo de direito comparado.

Por fim, verificar-se-á como delineou-se o processo de inserção da proteção ambiental junto a legislação pátria, por meio da inserção desses preceitos dentro da Carta Magna de 1988, com o objetivo de determinar como desenvolveu-se o processo de assimilação dos preceitos 


\section{A GLOBALIZAÇÃO E O PROCESSO DE DEGRADAÇÃO SOCIOAMBIENTAL}

A globalização assume não só características econômicas, mas também políticas, tecnológicas e culturais, que são dimensionadas pelos meios de comunicação. ${ }^{1}$ o fenômeno da globalização ${ }^{2}$ é responsável pela mudança na estrutura social em escala global, em especial, através da criação de processos econômicos que auxiliaram a expandir os "benefícios” gerados pelo capitalismo. A globalização econômica ${ }^{3}$ começa a ser implantada, de forma mais contundente, em meados de 1960, acelerando-se em nível mundial, com a fundação gradual de uma política neoliberal ${ }^{4}$, a partir do governo inglês, e seguida, posteriormente, pelos países hegemônicos.

Com a derrocada do socialismo, era necessário expandir as benesses do sistema capitalista para todas as nações. Assim, os países precisavam se adaptar à nova ordem econômica mundial, principalmente, os países periféricos. ${ }^{5}$ A política econômica globalizada mudaria a face das relações sócio-econômicas e culturais das nações.

\footnotetext{
${ }^{1}$ GIDDENS, Anthony. Mundo em descontrole: o que a globalização está fazendo de nós. 3.ed. Rio de Janeiro: Record, 2003.

2 Para Bauman “a 'globalização' está na ordem do dia; uma palavra da moda que se transforma rapidamente em um lema, uma encantação mágica, uma senha capaz de abrir as portas de todos os mistérios presentes e futuros. Para alguns, 'globalização' é o que devemos fazer se quisermos ser felizes; para outros, é a causa da nossa infelicidade. Para todos, porém, 'globalização' é o destino irremediável do mundo, um processo irreversível; é também um processo que nos afeta a todos na mesma medida e da mesma maneira. Estamos todos sendo 'globalizados' - e isso significa basicamente o mesmo para todos." BAUMAN, Zygmunt. Globalização: As consequencias humanas. Rio de Janeiro: Jorge Zahar Ed., 1999, p. 07.

${ }^{3} \mathrm{Na}$ acepção Santos "os traços principais dessa nova economia mundial são os seguintes: economia dominada pelo sistema financeiro e pelo investimento em escala global; processos de produção flexíveis e multilocais; baixos custos de transportes; revolução das tecnologias de informação e de comunicação; desregulação das economias nacionais; preeminência das agências financeiras multilaterais; emergência de três grandes capitalismos transnacionais: 0 americano, baseado nos EUA e nas relações privilegiadas deste país com o Canadá, o México e América Latina, o japonês, baseado no Japão e nas suas relações privilegiadas com os quatro pequenos tigres asiáticos e com o resto da Ásia; e o europeu, baseado na União Européia e nas relações privilegiadas desta com a Europa de Leste e com o Norte da África. Estas transformações têm vindo a atravessar todo o sistema mundial, ainda que com intensidade desigual consoante a posição dos países no sistema mundial." SANTOS, Boaventura de Sousa. Os processos da globalização. In.: (Org.). A globalização e as ciências sociais. São Paulo: Cortez Editora, 2011, p 29.

${ }^{4}$ A definição de política neoliberal tem por premissa o pensamento de Bedin (2002, p. 99) que afirma que esta
ocasionou "[...] um profundo corte nos gastos sociais, privatizações, desregulamentação da economia, aumento da
concentração de renda e, para finalizar, supressão ou tentativa de supressão de várias conquistas históricas do homem
trabalhador e do homem consumidor, ou seja, dos direitos econômicos e sociais." BEDIN, Gilmar Antônio Bedin. Os
direitos do homem e o neoliberalismo. 3.ed. Ijuí: Editora Unijuí, 2002, p. 99.
${ }^{5}$ lbid, 2002 , p. 98 - 101 .
} REDESG / Revista Direitos Emergentes na Sociedade Global - www.ufsm.br/redesg v. 3, n. 1, jan-jun/2014 
O CONSTITUCIONALISMO AMBIENTAL COMO MECANISMO REGULADOR DO EQUILÍBRIO SOCIOAMBIENTAL PARA AS GERAÇÕES PRESENTES E FUTURAS

A globalização da economia aumentou a desigualdade social, desencadeando uma crescente precarização nas condições de vida dos indivíduos. Seguindo essa lógica perversa, o Estado, sob um prisma neo-liberal, acaba por sonegar as condições estruturais no sentido de resguardar os direitos humanos e/ou fundamentais, essa situação acaba por afetar as questões socioambientais, tanto em nível local, como global, haja vista, que "a capacidade instrumental do Estado-Nação está comprometida de forma decisiva pela globalização das principais atividades econômicas, pela globalização da mídia e da comunicação eletrônica e pela globalização do crime."6

O processo de globalização econômica desencadeou uma verdadeira revolução na maneira de viver, criando uma sociedade baseada no consumo que fragiliza os vínculos entre os indivíduos, alterando assim sua interação social. Nessa senda, vislumbra-se "a maneira como a sociedade atual molda seus membros é ditada primeiro e acima de tudo pelo dever de desempenhar o papel de consumidor."7

Nesse novo modelo de sociedade calcado no consumo excessivo, o indivíduo, é destituído de seu papel de cidadão para assumir o papel de consumidor. Esse papel é incentivado pelo modelo econômico hegemônico, uma vez que, são necessários consumidores insaciáveis pela aquisição de novos bens de consumo. Assim, os consumidores necessitam estar “[...] em alerta sempre, continuamente expostos a novas tentações, num estado de excitação incessante - e também, com efeito, em estado de perpétua suspeita e pronta insatisfação."8 Sob essa perspectiva imposta pelo mercado, as empresas transnacionais, em especial, as alimentares, cosméticas e farmacêuticas buscam na natureza novos produtos para abastecer esses consumidores ávidos por produtos "inovadores", no intuito de atender/satisfazer suas necessidades. Nesse sentido, a “[...] sociedade de consumo ínsita-nos a viver num estado de perpétua carência, levando-nos a ansiar continuamente por algo que nem sempre podemos comprar." 9

Nesse cenário os Estados Unidos, Europa e Japão conhecidos como “utilizadores" de recursos biológicos, necessitam explorar a fauna e a flora, dos países "fornecedores", pois nestes estão localizadas as grandes reservas de biodiversidade, esse processo exploratório é

\footnotetext{
${ }^{6}$ CASTELLS, Manuel. A Sociedade em Rede. 6.ed. São Paulo: Paz e Terra, 1999, p. 288.

7 BAUMAN, Zygmunt. Globalização: As consequencias humanas, op. cit., p. 88.

${ }^{8}$ Ibid, 2002, p. 91.

9 LIPOVETSKY, Gilles. A sociedade da decepção. Barueri: Manole, 2007, p. 23.
}

REDESG / Revista Direitos Emergentes na Sociedade Global - www.ufsm.br/redesg v. 3, n. 1, jan-jun/2014 
O CONSTITUCIONALISMO AMBIENTAL COMO MECANISMO REGULADOR DO EQUILÍBRIO SOCIOAMBIENTAL PARA AS GERAÇÕES PRESENTES E FUTURAS

necessário para dar conta do consumo dos produtos cosméticos e farmacêuticos "naturais" e "biológicos" que cresce de forma avassaladora. ${ }^{10}$

Essa busca incessante por novas matérias primas para concepção de novos produtos deflagra um processo de degradação socioambiental, ocorre uma ruptura na relação entre homem/natureza. Nesse processo a natureza é relegada ao papel de coisa, e como coisa é permitida a sua livre manipulação no intuído de dominá-la. Assim, "[...] enquanto não for repensada a nossa relação com a natureza e enquanto não formos capazes de descobrir o que dela nos distingue e o que a ela nos liga, os nossos esforços serão em vão [...]."11

Esse processo ocasiona uma destruição da biodiversidade do país e/ou comunidade explorada, uma vez, que o setor privado, incentiva a monocultura do produto desejado, pois esse tipo de exploração é mais rentável. 0 incentivo a monocultura, cerceia o desenvolvimento econômico local, pois a população local é transformada em mão-de-obra barata, relegada ao papel de coleta da matéria prima. 0 caso do Ylang-Ylang ${ }^{12}$, As Comores, Arquipélago do Oceano Índico na costa de Madagascar é um exemplo dessa conseqüência nefasta da monocultura coletora.

Para manter a lógica do mercado calcada num modelo de sociedade consumista é preciso assegurar, a matéria prima para a confecção dos produtos, a consumidores que tenham poder aquisitivo para atender/satisfazer as suas necessidades. A iniciativa privada necessita do aporte dos Estados, para realização de políticas que atendam aos seus interesses, bem como do direito com mecanismo de regulação dos conflitos nestas áreas.

10 COLLECT/F ALTERNATIVE BIOPIRATERIE. Biopiratria: compreender, resistir, agir. Disponível em:
<http://www.biopiraterie.org/sites/default/files/etudes/Livret_Pt_040612.pdf>. Acesso em: 10 jun. 2013, p. 08-12.
11 OST, François. A natureza à margem da Lei: A ecologia à prova do Direito. Lisboa: Instituto, 1998, p. 09.
12 Elucidando o caso do Ylang-Ylang, “As Comores, arquipélago do Oceano Índico na costa de Madagascar, possuem
uma biodiversidade extremamente rica. As flores dessas ilhas conservam um tesouro que faz o orgulho de seus
habitantes: o Ylang-Ylang, 'a flor das flores', de perfume único. As Comores são os primeiros produtores mundiais da
essência dessas flores. Contudo, a riqueza produzida pela exploração do Ylang-Ylang recai muito pouco nas mãos dos
pequenos produtores - o lucro gerado escapa para o estrangeiro. O jornal comorense Albalad confirma 'Mal informados
sobre o impacto de sua atividade sobre o mundo, produtores e destiladores fornecem a baixo custo e por salários
ínfimos o ouro perfumado que fará a fortuna das casas de perfume do mundo inteiro. O circuito é composto de
produtores (que plantam e recolhem as flores), de destiladores (que extraem o óleo essencial, com uma técnica
arcaica) e dos compradores (empresas locais ou estrangeiras). O mercado é saturado, porque as empresas
compradoras são muito poucas, o que impede os produtores de fixar o preço mais conveniente para eles. Estas mãos
do trabalho silencioso estão na miséria, para a glória do Ylang-Ylang no estrangeiro'. A constante aqui é simples, a
exploração da biodiversidade pelas empresas estrangeiras reduzem os produtores locais a uma massa de mão de obra
barata que não beneficia, em nenhum dos casos, dos grandes lucros gerados pela exploração das plantas que colhem.
É extremamente visível o roubo de oportunidade de desenvolvimento conduzido pelas firmas estrangeiras."
COLLECT/F ALTERNATIVE BIOPIRATERIE, op. cit., p. 15 . REDESG / Revista Direitos Emergentes na Sociedade Global - www.ufsm.br/redesg v. 3, n. 1, jan-jun/2014 
No intuito de alterar esse cenário, em 1968, a Assembléia Geral da Organização das Nações Unidas, convoca os países membros para debater ações para refrear o crescente processo de degradação ambiental causado pelo homem, fato este, que colocaria em xeque a biodiversidade do planeta e a própria sobrevivência da espécie humana. ${ }^{13}$

Sob essa perspectiva, aconteceu a Conferência de Estocolmo em 1972, onde ocorreu o embate entre os países desenvolvidos, os quais asseveravam que o crescimento econômico acelerado dos países em desenvolvimento degradava a biodiversidade do planeta. E de outra banda, os países em desenvolvimento que alegavam que era necessário implantar uma agenda de crescimento econômico acelerado para suplantar as suas mazelas sociais. ${ }^{14}$

Apesar da propositura de uma agenda de ações para conter os efeitos da devastação ambiental em escala global, a questão fora abordada a partir de uma perspectiva antropocêntrica, ou seja, foi desconsiderada toda a cadeia ecológica e o homem fora colocado como centro da atividade no planeta. ${ }^{15}$

A consequencia dessa postura é o aumento da degradação ambiental, nos países fornecedores de material biológico, ou seja, os países em desenvolvimento, para manter o abastecimento das indústrias transnacionais que primam pela construção de "novos produtos" para manter o ciclo do consumo. Dessa forma, a questão do desenvolvimento sustentável ${ }^{16}$

\footnotetext{
${ }^{13}$ MILARÉ, Edis. Direito do Ambiente - doutrina, jurisprudência e glossário. 4.ed. Revista dos Tribunais. São Paulo, 2005.

14 Ibid, 2005.

15 Ibid, 2005.

${ }^{16}$ A terminologia de desenvolvimento sustentável será tratada na percepção de Freitas pontua que "[...] o princípio do desenvolvimento sustentável (ou da sustentabilidade, como se prefere), levado a bom termo, introduz gradativa e plasticamente, na sociedade e na cultura, um novo paradigma, que precisa reunir os seguintes aspectos nucleares: a) é determinação ética e jurídico-institucional (oriunda, no contexto brasileiro, diretamente da Constituição, especialmente dos artigos $3^{\circ}, 170$, IV e 225) de assegurar, às gerações presentes e futuras, o ambiente favorável ao bem-estar, monitorando por indicadores qualitativos, com a menor subjetividade possível; b) é determinação ética e jurídico-institucional de responsabilização objetiva do Estado pela prevenção e pela precaução, de maneira que se chegue antes dos eventos danosos, à semelhança do que sucede nos dispositivos antecipatórios biológicos; c) é determinação ética e jurídico-institucional de sindicabilidade ampliada das escolhas públicas e privadas de sorte a afastar cautelarmente vieses e mitos comuns, armadilhas falaciosas e o desalinhamento corriqueiro das políticas públicas, com vistas à promoção do desenvolvimento material e imaterial; d) é determinação ética e jurídicoinstitucional de responsabilidade pelo desenvolvimento de baixo carbono, compatível com os valores constantes no preâmbulo da Carta, os quais não se coadunam com a ânsia mórbida do crescimento econômico, considerado como fim em si. O que importa é a sustentabilidade nortear o desenvolvimento, não o contrário. Ou seja, uma releitura valorativa 'esverdeada' e de cores limpas de todo o ordenamento jurídico, não apenas do Direito Ambiental, é a chave em qualquer programa conseqüente de aplicação constitucional. De fato, se é certo que a nossa Carta está em consonância com os princípios da Carta das Nações Unidas, cumpre na vida real, exigir, por exemplo que os gastos públicos passem a respeitar a eficácia direta do desenvolvimento durável, de modo a serem efetivamente sopesados os custos e benefícios, diretos e indiretos (externalidades), sociais, econômicas e ambientais. Não por mera coincidência, no rol das diretrizes da Lei $\mathrm{n}^{\circ}$ 12.593, de 2012, que institui o Plano Plurianual da União, figura a promoção da sustentabilidade. Urge, porém, cobrar a sua cabal observância, por meio dos controles disponíveis
} REDESG / Revista Direitos Emergentes na Sociedade Global - www.ufsm.br/redesg v. 3, n. 1, jan-jun/2014 
passou a ser pauta recorrente no discurso de preservação ambiental, no intuito, de tentar combater a degradação ambiental ocasionada por esse processo de prospecção da biodiversidade.

Assim, a partir de 1980 os Estados hegemônicos, junto com algumas empresas transnacionais desencadeiam o processo de "modernização ecológica” a partir de uma visão neoliberal de "[...] conciliar o crescimento econômico com a resolução dos problemas ambientais dando ênfase à adaptação tecnológica, à celebração da economia de mercado, a crença na colaboração e no consenso."17

$\mathrm{Na}$ Conferência Rio- $92^{18}$ ocorre o debate sob a criação de uma agenda atinente a problemática ambiental e o desenvolvimento sustentável. Contudo, o debate é permeado pelos anseios do mercado no sentido de que as inovações tecnológicas trariam contribuições importantes para assegurar um modelo de desenvolvimento sustentável atrelado à lógica capitalista, ou seja, crescimento econômico e preservação ambiental. ${ }^{19}$

A partir dessa ótica neo-liberal dos países hegemônicos e das empresas transnacionais, a construção da política de preservação ambiental e do desenvolvimento sustentável passa a ser

(interno, externo, social e judicial)." FREITAS, Juarez. Sustentabilidade: Direito ao Futuro. Belo Horizonte: Fórum, 2012, p. 32-33.

${ }_{17}$ ACSELRAD, Henri; MELLO, Cecília Campello do A.; BEZERRA, Gustavo da Neves. O que é justiça ambiental. Rio de Janeiro: Garamond, 2009.

${ }^{18}$ Nesse sentido, "a Conferência das Nações Unidas sobre o Meio Ambiente e Desenvolvimento (CNUMAD), realizada em junho de 1992 no Rio de Janeiro, marcou a forma como a humanidade encara sua relação com o planeta. Foi naquele momento que a comunidade política internacional admitiu claramente que era preciso conciliar o desenvolvimento socioeconômico com a utilização dos recursos da natureza. Na reunião - que ficou conhecida como Rio-92, Eco-92 ou Cúpula da Terra -, que aconteceu 20 anos depois da primeira conferência do tipo em Estocolmo, Suécia, os países reconheceram o conceito de desenvolvimento sustentável e começaram a moldar ações com o objetivo de proteger o meio ambiente. Desde então, estão sendo discutidas propostas para que o progresso se dê em harmonia com a natureza, garantindo a qualidade de vida tanto para a geração atual quanto para as futuras no planeta. A avaliação partiu do pressuposto de que, se todas as pessoas almejarem o mesmo padrão de desenvolvimento dos países ricos, não haverá recursos naturais para todo mundo sem que sejam feitos graves - e irreversíveis - danos ao meio ambiente. Na Rio-92, chegou-se à conclusão de que temos de agregar os componentes econômicos, ambientais e sociais. Se isso não for feito, não há como se garantir a sustentabilidade do desenvolvimento - analisou na CRE, em março passado, Luiz Alberto Figueiredo Machado, coordenador-geral dos preparativos da Conferência Rio+20. 0 ambiente político internacional da época favoreceu a aceitação pelos países desenvolvidos de que as responsabilidades pela preservação do meio ambiente e pela construção de um convívio equilibrado com o planeta são diferentes. Na Rio-92, ficou acordado, então, que os países em desenvolvimento deveriam receber apoio financeiro e tecnológico para alcançarem outro modelo de desenvolvimento que seja sustentável, inclusive com a redução dos padrões de consumo - especialmente de combustíveis fósseis (petróleo e carvão mineral). Com essa decisão, a união possível entre meio ambiente e desenvolvimento avançou, superando os conflitos registrados nas reuniões anteriores patrocinadas pela ONU, como na Conferência de Estocolmo, em 1972." SENADO FEDERAL. Conferência Rio-92 sobre o meio ambiente do planeta: desenvolvimento sustentável dos países. Disponível em:< <http://www.senado.gov.br/noticias/Jornal/emdiscussao/rio20/a-rio20/conferencia-rio-92-sobre-omeio-ambiente-do-planeta-desenvolvimento-sustentavel-dos-paises.aspx>. Acesso em: 02 jan. 2014.

${ }^{19}$ ACSELRAD; MELLO; BEZERRA, O que é justiça ambiental, op. cit., 2009.

REDESG / Revista Direitos Emergentes na Sociedade Global - www.ufsm.br/redesg v. 3, n. 1, jan-jun/2014 
O CONSTITUCIONALISMO AMBIENTAL COMO MECANISMO REGULADOR DO EQUILÍBRIO SOCIOAMBIENTAL PARA AS GERAÇÕES PRESENTES E FUTURAS

delineada de forma homogênea, desconsiderado, em especial, as problemáticas regionais dos países não-hegemônicos. ${ }^{20}$

Nesse sentido, a questão evolvendo preservação ambiental e sustentabilidade passa a ser direcionada para áreas que não interfiram no modelo econômico posto, ou seja, no modelo capitalista. Assim, a busca pela criação de um modelo de desenvolvimento econômico alternativo, com vistas a resguardar o equilíbrio socioambiental para as gerações presentes e futuras esbarra em inúmeras dificuldades de implantação, uma vez, que vai contra a lógica do mercado.

\section{O CONSTITUCIONALISMO AMBIENTAL COMO MARCO REGULATÓRIO DO EQUILÍBRIO SOCIOAMBIENTAL PARA AS GERAÇÕES PRESENTES E FUTURAS}

As consequências dessas mudanças no paradigma social ocasionadas pela globalização são sentidas nas mais diversas áreas, em especial, no foco da nossa reflexão, no equilíbrio socioambiental. Nesse sentido, "a crise ambiental propiciou o surgimento de uma conflituosidade social intensa, até hoje existente, referente à necessidade de proteção ambiental."21

Assim, com vistas a resguardar nossa biodiversidade e promover um desenvolvimento que assegure o direito ao meio ambiente sadio e o equilíbrio socioambiental para gerações presentes e futuras faz-se necessário a concretização dos dispositivos constitucionais que resguardam a ordem ambiental. Dessa maneira, o Direito Constitucional exerce papel de protagonista na proteção da biodiversidade contra a exploração imposta pelo mercado a partir da inserção gradual de preceitos que visam tutelar a questão ambiental dentro das cartas constitucionais brasileiras no decorrer da nossa história.

Num primeiro momento, em 1934, o Direito Ambiental passa a incorporar a legislação pátria a partir da elaboração do primeiro Código Florestal Brasileiro que primava pela intervenção estatal para assegurar a proteção da biodiversidade, através de regras e limitações, para que os proprietários pudessem receber as terras devolutas do Estado. Era da incumbência

\footnotetext{
${ }^{20}$ ACSELRAD; MELLO; BEZERRA, O que é justiça ambiental, op. cit., 2009.

${ }^{21}$ LEITE, José Rubens Morato. Novas tendências e possibilidades do direito ambiental no Brasil. In: WOLKMER, Antonio Carlos; Os "novos" direitos no Brasil. Natureza e perspectivas. São Paulo: Saraiva, 2003, p. 183.
} 
O CONSTITUCIONALISMO AMBIENTAL COMO MECANISMO REGULADOR DO EQUILÍBRIO SOCIOAMBIENTAL PARA AS GERAÇÕES PRESENTES E FUTURAS

do "proprietário" resguardar a capacidade de produção das terras. Essa legislação carecia de mecanismos de efetivação e caiu em desuso. ${ }^{22}$

Assim, a partir de 1962, iniciam os trabalhos para a elaboração de um "novo" Código Florestal que tenta suprir a lacunas de seu antecessor. O novo Código Florestal trouxe poucas inovações e como seu antecessor não pontuou medidas políticas que auxiliassem na sua efetividade e no combate da degradação ambiental.

Por influência da Conferência de Estocolmo de 1972, em especial, do texto elencando no princípio dois ${ }^{23}$, os sistemas constitucionais de inúmeros países, inclusive o brasileiro, iniciam um processo de reforma dos mecanismos de tutela ambiental, a fim de resguardar o direito a um meio ambiente sadio e ecologicamente equilibrado.

No que tange o direito comparado relativo à questão ambiental, a Conferência de Estocolmo, afeta a construção das Constituições de países europeus como Grécia, Portugal e Espanha. Nessa senda, a Conferência de Estocolmo exerceu influência na elaboração do texto da Constituição do Chile, de 1972, que passou a primar por um meio ambiente sadio, cabendo ao Estado assegurar a efetivação desse direito. Nesse mesmo sentido, segue a Carta Constitucional do Panamá, de 1972, determinando o dever do Estado em propiciar um meio ambiente sadio. ${ }^{24}$

Já, a Constituição da lugoslávia, de 1974, assevera que é direito do homem ao meio ambiente sadio e cabe a comunidade social afiançar esse direito. A Constituição Chinesa, de 1978, elenca o Estado como protetor do meio ambiente. Bem como, a Constituição do Peru, de 1980, determina ao Estado resguardar o meio ambiente. Já, a partir da Conferência Rio-92 algumas cartas constitucionais, como a da França, passam por reformas no sentido de contemplar a Declaração do Rio-92 no aspecto da proteção ambiental. ${ }^{25}$

Ainda sob influência Conferência de Estocolmo, a Constituição Federal do Brasil de 1988 insere inúmeros dispositivos com vistas a tutelar o meio ambiente. Dessa forma, nossa Carta Magna, passa a incorporar dispositivos importantes no que tange a proteção ambiental, no seu art. $3^{\circ}$, onde estabelece os objetivos fundamentais da República Federativa do Brasil, em seu inciso II, determina "garantir o desenvolvimento nacional". Nota-se que a noção de

22 SOSFLORESTAS. Histórico do Código Florestal. Disponível em:<http://www.sosflorestas.com.br/historico.php>. Acesso em: 02 jan. 2014.

${ }^{23}$ A Conferência de Estocolmo relata no princípio dois que "os recursos naturais da terra incluídos o ar, a água, a terra, a flora e a fauna e especialmente amostras representativas dos ecossistemas naturais devem ser preservados em benefício das gerações presentes e futuras, mediante uma cuidadosa planificação ou ordenamento." MINISTÉRIO DO MEIO AMBIENTE. Declaração da Conferência de ONU no Ambiente Humano, op. cit., p. 03.

${ }_{24}^{24}$ MILARÉ, Edis. Direito do Ambiente - doutrina, jurisprudência e glossário, op. cit., 2005.

${ }^{25}$ Idid., 2005.

REDESG / Revista Direitos Emergentes na Sociedade Global - www.ufsm.br/redesg v. 3, n. 1, jan-jun/2014 
O CONSTITUCIONALISMO AMBIENTAL COMO MECANISMO REGULADOR DO EQUILÍBRIO SOCIOAMBIENTAL PARA AS GERAÇÕES PRESENTES E FUTURAS

desenvolvimento deve estar atrelada conforme preceitua o art. 170, inciso IV incorporando a "defesa do meio ambiente, inclusive mediante tratamento diferenciado conforme o impacto ambiental dos produtos e serviços e de seus processos de elaboração e prestação." 26

A Constituição Federal de 1988 também define um capítulo para abordar a questão do meio ambiente. Assim, a Carta Magna determina em seu art. 225, que todos têm direito ao meio ambiente equilibrado, que é função do Estado e da coletividade a sua preservação para as gerações presentes e futuras. Denota-se que a Constituição Federal de 1988, a partir da normatização da questão ambiental assume “[...] a consciência de que o direito à vida, como matriz de todos os demais direitos fundamentais do homem, é que há de orientar todas as formas de atuação no campo da tutela do meio ambiente." (SILVA, 2013, p. 774)

Nos referidos dispositivos constitucionais o legislador tenta atrelar o desenvolvimento econômico e a livre iniciativa de mercado com vistas a resguardar a biodiversidade e desenvolvimento sustentável. Nessa senda, apesar do texto constitucional assegurar o desenvolvimento sustentável não preceitua sob qual aspecto se dará essa efetiva proteção.

Nesse sentido, Veiga assegura que a sustentabilidade constitui-se “[...] numa fórmula sintética, consiste em assegurar, de forma inédita, as condições propicias ao bem-estar físico e psíquico no presente, sem empobrecer e inviabilizar o bem-estar no amanhã [...]."27 É perceptível que os referidos dispositivos constitucionais, que se refere ao "desenvolvimento sustentável" ainda possuem o ranço do capitalismo, haja vista, que não materializam o preceito da sustentabilidade.

Apesar da Constituição Federal, em seu art. $5^{\circ}$, § $1^{\circ}$ determinar a aplicação imediata dos direitos fundamentais, verifica-se a problemática da eficácia do preceito constitucional diante do "[...] crescente esvaziamento da força normativa dos textos constitucionais perante os novos esquemas regulatórios e as novas formas organizacionais e institucionais supranacionais."28

Assim, os direitos econômicos estão fora da alçada do Estado, e os direitos políticos resguardados pelo Estado estão “[...] estritamente limitados e circunscritos àquilo que Pierre Bourdieu batizou de pensée unique do livre mercado plenamente desregulado [...]." Já, de outra

\footnotetext{
${ }^{26}$ BRASIL. Constituição da República Federativa do Brasil. São Paulo: Saraiva, 2014, p. 136.

27 VEIGA, José Eli da. Desenvolvimento Sustentável: o desafio do século XXI. Rio de Janeiro: Garamond, 2005.

${ }^{28}$ FARIA, José Eduardo. O direito na economia globalizada. São Paulo: Malheiros Editores, 2002.

REDESG / Revista Direitos Emergentes na Sociedade Global - www.ufsm.br/redesg v. 3, n. 1, jan-jun/2014
} 
O CONSTITUCIONALISMO AMBIENTAL COMO MECANISMO REGULADOR DO EQUILÍBRIO SOCIOAMBIENTAL PARA AS GERAÇÕES PRESENTES E FUTURAS

banda "[...] os direitos sociais são substituídos um a um pelo dever individual do cuidado consigo mesmo e de garantir a si mesmo vantagens sobre os demais." 29

Nosso modelo jurídico calcado numa base racionalista serviu ao seu propósito, entretanto, dá sinais de exaurimento. 0 rompimento desse modelo passa indubitavelmente pela construção de um sistema jurídico capaz de articular os saberes, erigido a partir da teoria da complexidade na construção de novos aportes para a produção do conhecimento, em especial, a religação do conhecimento jurídico.

Nesse cenário pessimista, a tutela coletiva e difusa da questão ambiental deflagrada pelo art. 225 da Constituição Federal de 1988, assume extrema relevância, uma vez, que eleva a proteção do meio ambiente ao patamar de direitos fundamentais da terceira dimensão ${ }^{30}$. Dessa forma, "os direitos consagrados e reconhecidos pela Constituição designam-se, por vezes, direitos fundamentais formalmente constitucionais, porque eles são enunciados e protegidos por normas constitucionais." ${ }^{31}$

Nesse sentido, os mecanismos constitucionais assumem relevância diante da necessidade de implantar uma teoria geral do direito que possua a premissa de tutelar/materializar os "novos direitos", com ênfase, nos direitos ambientais. ${ }^{32}$ Portanto, percebe-se uma evolução na tutela desses direitos, pois "[...] a defesa coletiva do meio ambiente, consumidor, criança e adolescente, aposentado etc. há décadas atrás significaria abordar temas que não faziam parte real do mundo jurídico e muito menos do direito processual." 33

Para tanto, é necessário romper com a estagnação do sistema jurídico e do Estado nas questões ambientais, primando pela materialização de políticas públicas de desenvolvimento calcadas numa visão menos antropocentrista, no intuito "[...] impor limites ao mercado, por

\footnotetext{
${ }^{29}$ BAUMAN, Zygmunt. Identidade: entrevista a Benedetto Vecchi. Rio de Janeiro: Jorge Zahar Ed., 2005, p. 34-35.

${ }^{30}$ Para Sarlet "os direitos fundamentais da terceira dimensão, também denominados de direitos de fraternidade ou de solidariedade, trazem como nota distintiva o fato de se desprenderem, em princípio, da figura do home-indivíduo como seu titular, destinando-se a proteção de grupos humanos, família, povo, nação e, caracterizando-se, conseqüentemente como direitos de titularidade coletiva ou difusa." SARLET, Ingo Wolfgang. A eficácia dos direitos fundamentais. 11.ed. Porto Alegre: Livraria do Advogado, 2012, p. 58.

31 CANOTILHO, José Joaquim Gomes. Direito constitucional e teoria da Constituição. 6.ed. Coimbra: Livraria Almedina, 2002, p. 403.

32 WOLKMER, Antonio Carlos. Introdução aos fundamentos de uma teoria geral dos "novos" direito. In:

José Rubens Morato. Os “novos” direitos no Brasil. Natureza e perspectivas. São Paulo: Saraiva, 2003, p. 23.

${ }^{33}$ LEITE, José Rubens Morato. Interesses meta-individuais: conceitos - fundamentações e possibilidade de tutela. In.: OLIVEIRA JÚNIOR, José de R. M. (Org.) Cidadania Coletiva. Florianópolis: CPGD/Paralelo 27, 1986, p. 30-31.

REDESG / Revista Direitos Emergentes na Sociedade Global - www.ufsm.br/redesg v. 3, n. 1, jan-jun/2014
} 
O CONSTITUCIONALISMO AMBIENTAL COMO MECANISMO REGULADOR DO EQUILÍBRIO SOCIOAMBIENTAL PARA AS GERAÇÕES PRESENTES E FUTURAS

meio da participação do Estado, ou colocar limites em sua lógica” ${ }^{34}$ capitalista, primando pela construção de um modelo de desenvolvimento sustentável.

Nesse cenário, as solidificações dos preceitos ambientais consagrados na Carta Magna atuariam como mecanismo refreador da degradação ambiental, uma vez, que a Constituição emana "toda a autoridade, só nela encontra fundamento e só nela confere poderes e competências governamentais [...]."35 Assim, o constitucionalismo ambiental tem condições de atuar como marco regulatório para refrear a degradação ambiental provocada pelas relações de consumo e auxiliar a construção de um meio ambiente sadio e ecologicamente equilibrado para as gerações presentes e futuras.

\section{CONCLUSÃO}

O artigo buscou apontar a tensão ocasionada pelo processo de globalização a partir da ótica da sociedade de consumo, buscando verificar se a implantação de um constitucionalismo ambiental eficiente conseguiria atuar como mecanismo regulador desse conflito. No sentido de refrear a degradação ambiental, resguardando assim o direito a um meio ambiente sadio e ecologicamente equilibrado para as gerações presentes e futuras.

Para tanto, observou-se que o fenômeno da globalização econômica ocasionou uma transformação do estilo de vida em escala global, agora a sociedade está calcada no consumo. Essa nova ordem social acaba por precarizar a condição de vida do sujeito, que agora passa da sua condição de cidadão para a de consumidor. Nessa nova concepção de sociedade é necessário consumir, e para atingir esse intento, o mercado necessita criar "novos produtos" que demandam a degradação do meio ambiente, esse processo desenvolve-se através da prospecção de matérias primas para a confecção destes produtos.

Essa nova concepção social impende à implantação de um modelo de desenvolvimento sustentável desatrelado da lógica de mercado, ou seja, o desenvolvimento econômico acompanhado de mecanismos que viabilizem a preservação socioambiental. Para tentar contrapor essa lógica a Conferência de Estocolmo e a Rio-92, tentam implantar uma agenda

\footnotetext{
${ }^{34}$ LEITE, José Rubens Morato. Novas tendências e possibilidades do direito ambiental no Brasil. In: WOLKMER, Antonio Carlos;__. Os "novos" direitos no Brasil. Natureza e perspectivas, op. cit., 2003, p. 189.

${ }^{35}$ SILVA, José Afonso da. Curso de Direito Constitucional Positivo. 36.ed. rev. atual. São Paulo: Malheiros Editores Ltda, 2013, p. 49-50.

REDESG / Revista Direitos Emergentes na Sociedade Global - www.ufsm.br/redesg v. 3, n. 1, jan-jun/2014
} 
O CONSTITUCIONALISMO AMBIENTAL COMO MECANISMO REGULADOR DO EQUILÍBRIO SOCIOAMBIENTAL PARA AS GERAÇÕES PRESENTES E FUTURAS

mundial de combate da degradação ambiental. Contudo, essa agenda não conseguiu se desvencilhar de uma visão antropocêntrica para realizar tal intento, nesse sentido, continua ainda atrelada à lógica do mercado.

Nesse ínterim, verificou-se a contaminação dos sistemas constitucionais contemporâneos por mecanismos de proteção da tutela ambiental, oriundos, em especial, da Conferência de Estocolmo. Para tanto, realizou-se uma breve análise dos dispositivos inseridos em algumas cartas constitucionais que passaram a resguardar a tutela ambiental.

Nessa nova perspectiva, pontuo-se a inserção na legislação pátria da proteção da tutela ambiental, dando especial ênfase, aos dispositivos inseridos na Constituição Federal de 1988, que passa a atuar como marco regulatório do meio ambiente. Entretanto, para a materialização desse princípio é necessária uma atuação mais incisiva do poder político, no sentido de criar políticas públicas eficientes com o condão de garantir a concretização do equilíbrio socioambiental.

Por fim, verificou-se que o constitucionalismo ambiental pode atuar como marco regulatório do equilíbrio socioambiental para as gerações presentes e futuras, regulando em especial, a degradação ambiental provocada pelas relações de consumo. Contudo, faz-se necessário repensar o direito, em especial, os preceitos constitucionais que resguardam o meio ambiente, no sentido de que este venha de encontro aos anseios da preservação e manutenção de um meio ambiente sadio e ecologicamente equilibrado para as gerações presentes e futuras.

\section{REFERÊNCIAS}

ACSELRAD, Henri; MELLO, Cecília Campello do A.; BEZERRA, Gustavo da Neves. O que é justiça ambiental. Rio de Janeiro: Garamond, 2009.

BAUMAN, Zygmunt. Identidade: entrevista a Benedetto Vecchi. Rio de Janeiro: Jorge Zahar Ed., 2005.

. Globalização: As consequencias humanas. Rio de Janeiro: Jorge Zahar Ed., 1999.

BEDIN, Gilmar Antônio Bedin. Os direitos do homem e o neoliberalismo. 3.ed. Ijuí: Editora Unijuí, 2002.

BRASIL, Constituição da República Federativa do Brasil. São Paulo: Saraiva, 2014.

CASTELLS, Manuel. A Sociedade em Rede. 6.ed. São Paulo: Paz e Terra, 1999.

REDESG / Revista Direitos Emergentes na Sociedade Global - www.ufsm.br/redesg v. 3, n. 1, jan-jun/2014 
O CONSTITUCIONALISMO AMBIENTAL COMO MECANISMO REGULADOR DO EQUILÍBRIO SOCIOAMBIENTAL PARA AS GERAÇÕES PRESENTES E FUTURAS

CANOTILHO, José Joaquim Gomes. Direito constitucional e teoria da Constituição. 6.ed. Coimbra: Livraria Almedina, 2002.

COLLECT/F ALTERNATIVE BIOPIRATERIE. Biopiratria: compreender, resistir, agir. Disponível em: <http://www.biopiraterie.org/sites/default/files/etudes/Livret_Pt_040612.pdf>. Acesso em: 10 jun. 2013.

DEMO, Pedro. Sociologia: uma introdução crítica. 2.ed. São Paulo: Atlas, 1985.

FARIA, José Eduardo. O direito na economia globalizada. São Paulo: Malheiros Editores, 2002.

FREITAS, Juarez. Sustentabilidade: Direito ao Futuro. Belo Horizonte: Fórum, 2012.

GIDDENS, Anthony. Mundo em descontrole: o que a globalização está fazendo de nós. 3.ed. Rio de Janeiro: Record, 2003.

LEITE, José Rubens Morato. Novas tendências e possibilidades do direito ambiental no Brasil. In: WOLKMER, Antonio Carlos;

Paulo: Saraiva, 2003.

. Interesses meta-individuais: conceitos - fundamentações e possibilidade de tutela. In.: OLIVEIRA JÚNIOR, José de R. M. (Org.) Cidadania Coletiva. Florianópolis: CPGD/Paralelo 27, 1986.

LIPOVETSKY, Gilles. A sociedade da decepção. Barueri: Manole, 2007.

MILARÉ, Edis. Direito do Ambiente - doutrina, jurisprudência e glossário. 4.ed. Revista dos Tribunais. São Paulo, 2005.

MINISTÉRIO DO MEIO AMBIENTE. Declaração da Conferência de ONU no Ambiente Humano Disponível em: <www.mma.gov.br/estruturas/agenda21/_arquivos/estocolmo.doc>. Acesso em: 02 jan. 2014

OST, François. A natureza à margem da Lei: A ecologia à prova do Direito. Lisboa: Instituto, 1998.

SARLET, Ingo Wolfgang. A eficácia dos direitos fundamentais. 11.ed. Porto Alegre: Livraria do Advogado, 2012.

SANTOS, Boaventura de Sousa. Os processos da globalização. In.: (Org.). $A$ globalização e as ciências sociais. São Paulo: Cortez Editora, 2011.

SENADO FEDERAL. Conferência Rio-92 sobre o meio ambiente do planeta: desenvolvimento sustentável dos países. Disponível em:< <http://www.senado.gov.br/noticias/Jornal/emdiscussao/rio20/a-rio20/conferencia-rio-92- 
ISSN 2316-3054

(DOI): $10.5902 / 2316305413694$

O CONSTITUCIONALISMO AMBIENTAL COMO MECANISMO REGULADOR DO EQUILÍBRIO SOCIOAMBIENTAL PARA AS GERAÇÕES PRESENTES E FUTURAS

LUÍS MARCELO MENDES

sobre-o-meio-ambiente-do-planeta-desenvolvimento-sustentavel-dos-paises.aspx>. Acesso em: 02 jan. 2014.

SILVA, José Afonso da. Curso de Direito Constitucional Positivo. 36.ed. rev. atual. São Paulo: Malheiros Editores Ltda, 2013.

SOSFLORESTAS. Histórico do Código Florestal. Disponível em:<http://www.sosflorestas.com.br/historico.php>. Acesso em: 02 jan. 2014.

VEIGA, José Eli da. Desenvolvimento Sustentável: o desafio do século XXI. Rio de Janeiro: Garamond, 2005.

WOLKMER, Antonio Carlos. Introdução aos fundamentos de uma teoria geral dos "novos" direito. In:___ _ LEITE, José Rubens Morato. Os “novos” direitos no Brasil. Natureza e perspectivas. São Paulo: Saraiva, 2003.

Recebido em: 01/05/2014 Revisões em: 15/09/2014 Aprovado em: 20/10/2014 